\title{
The factors affecting morbidity and mortality in spontaneous intracerebral hematomas.
}

\author{
Ömer Aykanat ${ }^{1 *}$, Metin Ocak ${ }^{2}$ \\ ${ }^{1}$ Department of Neurosurgery, Medical Faculty, Ahi Evran University, Kırsehir, Turkey \\ ${ }^{2}$ Department of Emergency, Medical Faculty, Ahi Evran University, Kursehir, Turkey
}

\begin{abstract}
Objective: In this study, 33 patients with a diagnosis of spontaneous intracerebral hematomas were investigated retrospectively and factors affecting morbidity and mortality were determined.

Materials and methods: In this study, 33 patients with a diagnosis of SIH in intensive care unit (ICU) of Ahi Evran University Medical Faculty Hospital were retrospectively reviewed between the dates of 01.09.2016 and 30.11.2017. The factors affecting morbidity and mortality in these patients were studied in detail by reviewing the patients' age, gender, admission condition, GCS score, personal background, hematoma location, hematoma volume, presence/absence of intraventricular hemorrhage, type of therapy and discharge condition.

Results: The study included 18 female $(54.5 \%)$ and 15 male patients $(45.5 \%)$ whose ages were in the range of 43-91. Seen in 21 patients $(63.6 \%)$, blackout was the leading cause for the admission. As a result of the neurological examination on admission, of all the patients, GCS scores of 11 patients $(33.3 \%)$ were in the range of 3-7; it was between 8-13 in 17 patients (51.5\%) and between 14-15 in 5 patients (15.1\%). When their personal bacgrounds were reviewed, hypertension in 19 patients $(57.6 \%)$ was seen as the most common etiological factor. We observed lobar region was the most frequent site for the spontaneous intracerebral hematomas. 3 patients $(9.1 \%)$ were applied surgical operation, 4 patients $(\mathbf{1 2 . 1 \% )}$ were applied External Ventricular Drainage and 26 patients $\mathbf{( 7 8 . 8 \% )}$ ) were followed up with medical treatment. The follow-up length of the patients varied in the range of 3-72 days. While 13 patients $(39.4 \%)$ were discharged with a full-recovery and 5 patients with morbidity $(15 . \%)$, the other 15 patient $(\mathbf{4 5 . 5 \%})$ died.

Conclusion: As a conclusion, it could be said that while hematoma volume, hematoma location and presence/absence of intraventricular hemorrhages have significant effect on morbidity and mortality in SIHs, the most significant factor is the patients' GCS on admission. In our study, age had no significant effect on mortality and morbidity.
\end{abstract}

Keywords: Intracerebral hematoma, Spontaneous, Morbidity, Mortality.

\section{Introduction}

Spontaneous intracerebral hematomas (SIHs), which are intraparenchymal hemorrages result from various nontraumatic causes, were first defined by Charles Baplesy in 1932 [1]. Being one of the leading causes of cerebrovascular diseases and having about 15/10.000 rate of incidence, SIHs has a 50\% monthly mortality rate [2]. Etiology of SIHs comprise of such vascular pathologies as anti-coagulant usage, amyloid angiopathy, anteriovenous malformation and use of alcohol. However, the most common etiological factor is hypertension (HT) $[3,4]$. The condition of the patients during emergency ward admission varies depending on the volume and location of hematoma and the age of patient. However, the disease prognosis, vary by Glasgow Coma Scale (GCS) during hospital admission, presence/absence of intraventricular hemorrhage and comorbid diseases [5]. While the golden standard is brain Computed Tomography (CT) for diagnosis, in some cases Magnetic Resonance Imaging (MRI) can also be used. Surgical or medical therapy can be chosen for treatment depending on the age of patient, GCS score, location and volume of hematoma.

In this study, 33 patients with a diagnosis of SIH in intensive care unit (ICU) of Ahi Evran University Medical Faculty Hospital were retrospectively examined and the factors affecting morbidity and mortality in the patients were studied with literature between the dates of 01/09/2016 and 30/11/2017. 


\section{Materials and Methods}

In this study, 33 patients with a diagnosis of SIH in intensive care unit (ICU) of Ahi Evran University Medical Faculty Hospital were retrospectively reviewed between the dates of 01/09/2016 and 30/11/2017. The factors affecting morbidity and mortality in these patients were studied in detail by reviewing the patients' age, gender, admission condition, GCS score, personal background, hematoma location, hematoma volume, presence/absence of intraventricular hemorrhage, type of therapy (surgical or medical) and discharge condition. In our study, we reviewed spontaneous supratentorial hematomas but we excluded infratentorial and traumatic ones and the ones caused by tumor and vascular malformation.

The ethical approval was obtained from the ethics committee of Medical Faculty in Ahi Evran University on 13/02/2018 with 2018-03/36 code number.

\section{Results}

The study included 18 female (54.5\%) and 15 male patients (45.5\%) whose ages were in the range of 43-91 and the mean age was 70 . Seen in 21 patients $(63.6 \%)$, blackout was the leading cause for the admission, followed by hemiparesis in right/left part of body seen in 9 patients $(27.3 \%)$ and headache seen in 7 patients $(21.2 \%)$ respectively. As a result of the neurological examination on admission, of all the patients, GCS scores of 11 patients $(33.3 \%)$ were in the range of $3-7$; it was between $8-13$ in 17 patients $(51.5 \%)$ and between $14-15$ in 5 patients $(15.1 \%)$. When their personal bacgrounds were reviewed, hypertension (HT) in 19 patients (57.6\%) was seen as the most common etiological factor, followed by anticoagulant use $(36.4 \%)$ and 5 patients $(15.1 \%)$ had no any case history. All the patients were diagnosed with brain CT. We observed lobar hematoma in 16 patients (48.5\%); thalamic hematoma in 14 patients $(42.4 \%)$ and basal ganglia hematoma in 3 patients $(9.1 \%)$. Moreover, we observed the presence of intravenricular hemorrhage in 10 out of 17 patients having thalamic and basal ganglia hematomas. The size of hematomas were calculated by measuring $x-y-z$ axes on $\mathrm{CT}$ images (Figure 1). The volume of hematomas were seen to be in the range of 1 $\mathrm{ml}-105 \mathrm{ml}$ and the average volume was $19.6 \mathrm{ml} .3$ patients (9.1\%) were applied surgical operation (hematoma evacuation by craniotomy); 4 patients $(12.1 \%)$ were applied External Ventricular Drainage (EVD) and 26 patients (78.8\%) were followed up with medical treatment. The follow-up length of the patients varied in the range of 3-72 days. While 13 patients (39.4\%) were discharged with a full-recovery and 5 patients with morbidity $(15.1 \%)$, the other 15 patients $(45.5 \%)$ died (Table 1).

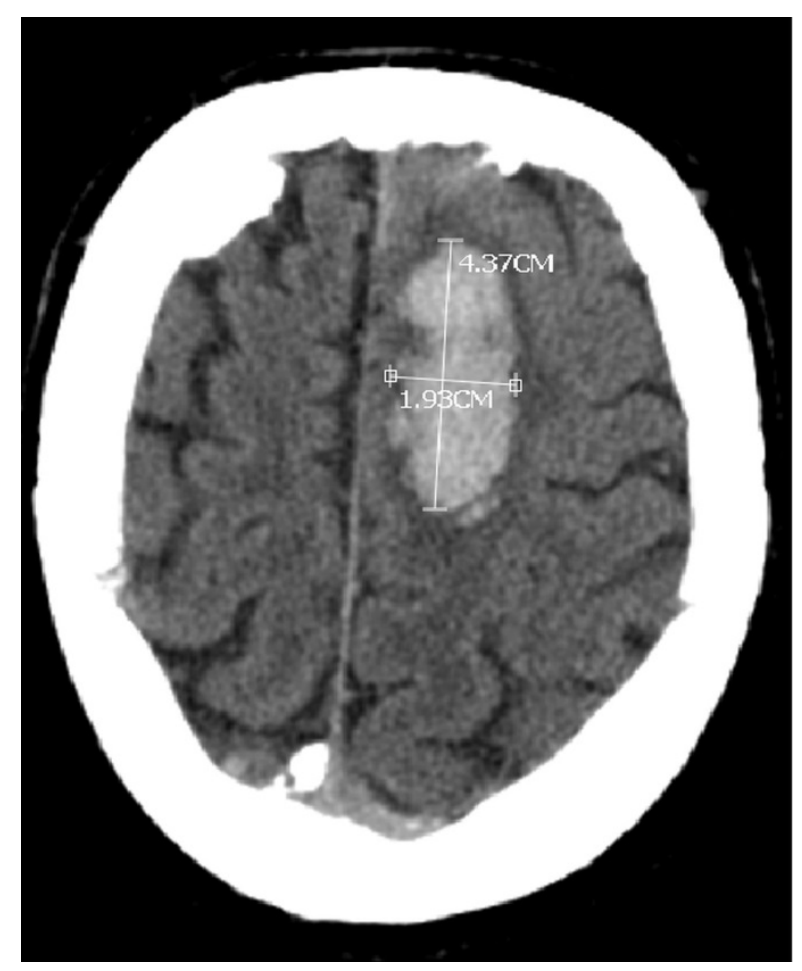

Figure 1. The size of hematomas, calculated by measuring $x-y-z$ axes on CT image.

The age range of the patients discharged with full-recovery was 48-91 and the average age was 69. Their GCSs on admission were in the range of 12-15. While 9 out of these 13 patients had lobar hematomas and 1 patient had basal ganglia hematoma, the others had thalamic hematomas. The hematoma volumes were between $1 \mathrm{ml}-30 \mathrm{ml}$ and the average value was $10.2 \mathrm{ml}$. We observed presence of intraventricular hemorrhage only in 1 out of 4 patients who had thalamic and basal ganglia hematomas. Age range of the patients disharged with morbidity was 43-77 and the average age was 66.6. Their GCS range was 7-12 on admission. While 1 out of 5 patients had lobar hematoma, the other 4 ones had thalamic hematomas. The hematoma volumes were between $7.5 \mathrm{ml}-75 \mathrm{ml}$ and the average value was $28.8 \mathrm{ml}$. We observed presence of intraventricular hemorrhage only in 2 out of 4 patients who had thalamic hematomas. Age range of the patients having died was 53-91 and the average age was 69.6. Their GCS range was 3-11 on admission. While 4 out of 15 patients had lobar hematoma, 9 patients had thalamic hematomas, the other 2 ones had basal ganglia hematomas. The hematoma volumes were between $2 \mathrm{ml}-105 \mathrm{ml}$ and the average value was $25.8 \mathrm{ml}$. We observed presence of intraventricular hemorrhage only in 7 out of 11 patients who had thalamic and basal ganglia hematomas.

Table 1. Distribution of the patients' age, gender, complaints, GCS, case history and discharce condition and the distribution of localization and volume of hematomas and presencelabsence of intraventricular hemorrhage.

\begin{tabular}{llll}
\hline Age Gender Complaint & $\begin{array}{l}\text { GCS on Case History } \\
\text { Admission }\end{array}$ & $\begin{array}{l}\text { Localization } \\
\text { Volume }\end{array}$ & $\begin{array}{l}\text { Presence/Absence of Outcome } \\
\text { Intraventricular } \\
\text { hemorrhage }\end{array}$
\end{tabular}


The factors affecting morbidity and mortality in spontaneous intracerebral hematomas

\begin{tabular}{|c|c|c|c|c|c|c|c|c|}
\hline 74 & $\mathrm{~F}$ & blackout & 4 & $\mathrm{HT}$ & Left thalamic & 22.5 & + & Exitus \\
\hline 91 & $\mathrm{~F}$ & blackout & 13 & HT, Aspirin & Left parietal & 7.5 & - & Full recovery \\
\hline 85 & $\mathrm{~F}$ & $\begin{array}{l}\text { blackout, } \\
\text { hemiparesis }\end{array}$ & 9 & HT, Coraspin & Left parietooccipital & 18 & - & Exitus \\
\hline 84 & $M$ & blackout & 12 & HT & Right thalamic & 6 & + & Full recovery \\
\hline 78 & $\mathrm{~F}$ & $\begin{array}{l}\text { blackout, } \\
\text { hemiparesis }\end{array}$ & 4 & DM & Left thalamic & 33 & + & Exitus \\
\hline 56 & $\mathrm{~F}$ & blackout & 3 & Coraspin & Right thalamic & 15 & + & Exitus \\
\hline 71 & $\mathrm{~F}$ & blackout & 4 & $\mathrm{HT}$ & Left parietal & 12 & - & Exitus \\
\hline 68 & $\mathrm{~F}$ & blackout, Headache & 13 & CAD, AF, Coraspin & Left frontal & 15 & - & Full recovery \\
\hline 77 & $\mathrm{~F}$ & $\begin{array}{l}\text { Headache , Left } \\
\text { hemiparesis }\end{array}$ & 12 & CVA, ARF, Coraspin & Right temporal & 24 & - & Morbid \\
\hline 75 & M & blackout & 7 & HT, CVA, Coraspin & Left temporoparietal & 75 & - & Morbid \\
\hline 60 & $M$ & blackout & 5 & $\mathrm{HT}$, Aspirin & Left thalamic & 2 & + & Exitus \\
\hline 53 & M & Headache & 14 & No case history & Left parietal & 30 & - & Full recovery \\
\hline 79 & $\mathrm{~F}$ & blackout & 5 & CVA, Aspirin & Left thalamic & 50 & + & Exitus \\
\hline 75 & M & blackout & 9 & No case history & Right thalamic & 7.5 & + & Morbid \\
\hline 74 & $\mathrm{~F}$ & blackout & 5 & HT & Left thalamic & 20 & + & Exitus \\
\hline 49 & $\mathrm{~F}$ & Facial Paresthesia & 15 & HT & Left parietal & 13.5 & - & Full recovery \\
\hline 77 & M & blackout, Left hemiparesis & 12 & HT & Right thalamic & 6 & - & Full recovery \\
\hline 76 & $M$ & Left hemiparesis & 13 & No case history & Right parietal & 13.5 & - & Full recovery \\
\hline 43 & $\mathrm{~F}$ & Right hemiparesis & 10 & HT & Left thalamic & 24 & - & Morbid \\
\hline 48 & M & $\begin{array}{l}\text { Headache, } \\
\text { hemiparesis }\end{array}$ & 13 & No case history & Right basal ganglia & 2 & - & Full recovery \\
\hline 59 & $\mathrm{~F}$ & Gait and speech disorder & 12 & HT & Left parietal & 18 & - & Full recovery \\
\hline 81 & $M$ & Left hemiparesis & 12 & Dementia, Aspirin & Right temporal & 8 & - & Full recovery \\
\hline 55 & $\mathrm{~F}$ & blackout & 9 & No case history & Left basal ganglia & 15 & - & Exitus \\
\hline 91 & $\mathrm{~F}$ & blackout & 11 & $\mathrm{HT}$, Aspirin & Left frontal & 3 & - & Exitus \\
\hline 56 & M & Drowsiness & 14 & No case history & Left frontal & 6 & - & Full recovery \\
\hline 66 & M & Diplopia, Drowsiness & 14 & HT & Right thalamic & 7 & - & Full recovery \\
\hline 61 & M & blackout, Left hemiparesis & 11 & HT & Right thalamic & 18 & - & Exitus \\
\hline 55 & M & blackout & 6 & CVA, Aspirin, Alcohol & Left thalamic & 45 & + & Exitus \\
\hline 79 & $\mathrm{~F}$ & blackout & 6 & HT & Right parietal & 105 & - & Exitus \\
\hline 80 & $\mathrm{~F}$ & blackout & 8 & HT, Aspirin & Left basal ganglia & 4 & - & Exitus \\
\hline 90 & M & Headache, Drowsiness & 14 & HT & Right parietal & 1 & - & Full recovery \\
\hline 63 & M & $\begin{array}{l}\text { blackout, } \\
\text { hemiparesis }\end{array}$ & 11 & $\mathrm{HT}, \mathrm{DM}$ & Left thalamic & 13.5 & + & Morbid \\
\hline 77 & $\mathrm{~F}$ & blackout & 5 & HT & Right temporal & 24.5 & - & Exitus \\
\hline
\end{tabular}

GCS: Glasgow Coma Score; HT: Hypertension; DM: Diabetes Mellitus; CAD: Coronary Artery Disease; AF: Atrial Fibrilation; CVA: Cerebrovascular Accident; ARF: Acute Renal Failure 


\section{Discussion and Conclusion}

Spontaneous Intracerebral Hematomas (SIHs), which are defined as intraparenchymal hemorrhage without trauma, has an average incidence rate of $15 / 100000$ but the rate has been indicated to vary in the range of 12-51.8/100000 [5-10]. About one fifth of SIHs are supratentorial. Some studies have indicated that SIHs occur more frequently in $5^{\text {th }}$ and $6^{\text {th }}$ decades of lifespan and are seen more in males and gender has no significant effect on mortality [4-6,11]. As opposed to literature, in our case serial, $72.7 \%$ of the patients had ages in and above 7 th decade and $80 \%$ of the 15 patients who died were females. The most significant risk factor is HT in literature, followed by old age, use of anticoagulant, DM (diabetes mellitus), alcohol, obesity, vascular malformations and amiloid angiopathy [12-14]. In our study, HT and use of anticoagulant took the first and second place as etiological factors with their rate of $57.6 \%$ and $36.4 \%$ respectively, which is compatible with literature. The fact that there was no risk factor for $15.1 \%$ of the patients is quite interesting but it should be kept in mind that a sudden HT attack might have occurred in these patients.

There are variations in localization of SIHs. While some studies point out basal ganglia and thalamic region, others refer to lobar region as the most common location for SIHs [15-18]. The variation might be caused by the geographical conditions of the region where the study is conducted; feeding habits of the patients and racial differences. One common point in all studies conducted up to now is that they indicate basal ganglia and thalamic regions as the most common location for HTinduced SIHs. However, in our study, lobar region was the most common location with a rate of $48.5 \%$, which was followed by thalamic and ganglia regions with degressive rates respectively. As opposed to literature, we observed thalamic hematomas in $50 \%$ of the patients who had no anticoagulant use but HT trouble in their case histories and lobar hematoma in the other half. Furthermore, $66.6 \%$ of six patients who had both anticoagulant use and HT in their case histories were observed to have lobar hematomas and the remaining ones to have thalamic and basal ganglia hematomas. Since brain CT has high diagnostic value in acute hemorrhages and is easily accessible, it is the gold standard method for diagnosis of $\mathrm{SIH}$ which itself is a kind of acute hemorrhage as well. However, in tumor and vascular malformation-induced hemorrhages, MRI could be used to explain the underlying causes. Since we excluded tumor and vascular malformation-induced hemorrhages from our study, we used only brain CT for diagnosis in all patients in the study.

The type of treatment in SIHs could be surgical (evacuation of hematoma via craniotomy or external ventricular drainage (EVD) or medical. The type of treatment varies depending on the age, GCS on admission, volume of hematoma, presence/ absence of intraventricular hemorrhage and location of hematoma. Several studies have stated that the volume of hematoma, presence/absence of intraventricular hemorrhage and location of hematoma are fairly significant forpatients' prognosis [15,18-21]. In some studies, $>30 \mathrm{ml}$ hematomas were more effective on morbidity and mortality while in others presence/absence of intraventricular hemorrhage or location (thalamic and basal ganglia hematomas) of hematomas had more effect on them. The primary aim of medical treatment is to bring intracranial and cerebral perfusion pressures back to normal or at least near-normal values, to stabilize the vital signs of patients and to assure epileptic attack prophylaxis. Whereas, the primary aim of surgical treatment is to evacuate hematoma and to eliminate its pressure on surrounding parenchyma tissue and as a result to decrease intracranial pressure and reduce secondary cerebral damage. Ultimate aim of the both treatment types is to minimize morbidity and mortality. In our case study, 3 patients were applied hematoma evacuation via craniotomy; 4 patients were applied EVD and the others were followed up with medical treatment. The type of treatment was determined by the volume of hematoma, presence/absence of midline shift, neurologic state of the patient, regression in the presence of intraventricular hemorrhage and development hydrocephalus.

Many earlier studies have suggested that many SIHs have poor prognosis and the average mortality rate is in the range of $34-50 \%$ in SIHs regardless of the type of the treatment $[15,19,21]$. In our case serial, the average mortality rate was $45.5 \%$, which was compatible with literature. While one of the 3 patients who had surgical treatment died, one of them was discharged with morbidity and one was discharged with full recovery. While all of 4 patients who were applied EVD died, only 10 out of 26 patients followed up with medical treatment died. In our case serial, the patients having $>30 \mathrm{ml}$ hematoma volume in thalamic and basal ganglia hematomas were observed to have higher morbidity and mortality rate. All the patients, regardless of outcome (full-recovery, morbidity, mortality), had both deep (basal ganglia and thalamic) and superficial (lobar) hematomas in terms of localization; $>30 \mathrm{ml}$ and $<30 \mathrm{ml}$ hematomas in terms of volume; present and absent of intraventricular hemorrhages. Age had no significant effect on morbidity, mortality or full-recovery. However, the patients discharged with full recovery were observed to have $\geq 12$ GCS on admission while morbid or mortal patients had $\leq 11$ GCS.

As a conclusion, it could be said that while hematoma volume, hematoma location and presence/absence of intraventricular hemorrhages have significant effect on morbidity and mortality in SIHs, the most significant factor is the patients' GCS on admission. In our study, age had no significant effect on mortality and morbidity.

\section{References}

1. Ozer F, Elmacı İ, Aysal F, Ataklı D, Arpacı B. spontaneous intracerebral hematoma: Analysis of 177 cases. J Dusunen Adam 1991; 4: 64-70.

2. Ariesen MJ, Claus SP, Rinkel GJE, Algra A: Risk Faktors for intracerebral hemorrhage in the general population. Stroke 2003; 34: 2060.

3. Ovül I, Tucbay E, Mutluer S. Spontaneous intraparenchymal hematomas. Cerebrovascular Diseases. Izmir, EÜTF Publishing House 1985; 209-221. 
4. Qureshi AI, Giles WH, Croft JB. Racial differences in the incidence of intracerebral hemorrhage: Effects of blood pressure and education. Neurology 1999; 52: 1617-1621.

5. Anderson CS, Chakera TMH, Stewart-Wynne EG, Jamrozik KD. Spectrum of primary intracerebral haemorrhage in Perth, Western Australia, 1989-1990: incidence and outcome. J Neurol Neurosurg Psychiatry 1994; 57: 936-940.

6. Van Asch CJ, Luitse MJ, Rinkel GJ, van der Tweel I, Algra A, Klijn CJ. Incidence, case fatality, and functional outcome of intracerebral haemorrhage over time, according to age, sex, and ethnic origin: A systematic review and meta-analysis. Lancet Neurol 2010; 9: 167-176.

7. Broderick JP, Brott T, Tomsick T, Huster G, Miller R. The risk of subarachnoid and intracerebral hemorrhages in blacks as compared with whites. N Engl J Med 1992; 326: 733-736.

8. Broderick JP, Brott T, Tomsick T, Miller R, Huster G. Intracerebral hemorrhage more than twice as common as subarachnoid hemorrhage. J Neurosurg 1993; 78: 188-191.

9. Giroud M, Gras P, Chadan N, Beuriat P, Milan C, Arveux P, Dumas R. Cerebral haemorrhage in a French prospective population study. J Neurol Neurosurg Psychiatry 1991; 54: 595-598.

10. Qureshi AI, Giles WH, Croft JB. Racial differences in the incidence of intracerebral hemorrhage: effects of blood pressure and education. Neurology 1999; 52: 1617-1621.

11. Little KM, Alexander MJ. Medical versus surgical therapy for spontaneous intracranial hemorrhage Neurosurg Clin N Am 2002; 13: 339-347.

12. Raymond TFC, Liang-Yu Z. Use of original, modified or new intracerebral hemorrhage score to predict mortality and morbidity after intracerebral hemorrhage. Stroke 2003; 34: 1717.

13. Ruiz-Sandoval JL, Ortega-Alvarez L, García-Navarro V, Romero-Vargas S, González-Cornejo S. Intracerebral haemorrhage in a referral hospital in the central-western region of Mexico. Rev Neurol 2005; 40: 656-660.

14. Skidmore CT, Andrefsky J. Spontaneous intracerebral hemorrhage: epidemiology, pathophysiology, and medical management. Neurosurg Clin N Am 2002; 13: 281-288.

15. Cole FM, Yates PO. Intracerebral microaneurysms and small cerebrovascular lesions. Brain 1967; 90: 759-768.

16. Thomas BD: Spontaneous intracerebral hemorrhage. Neurosurgery 1985; 1510-1517.

17. Kase CS. Intracerebral hemorrage: Non-hypertensive causes. Stroke 1986; 17: 590-594.

18. Eroglu A, Atabey C, Topuz KA, Colak A, Demircan N. Evaluation of 104 cases with spontaneous intracerebral hematoma. J Turk Norosirurji 2012; 22: 167-170.

19. Kase CS, Mohr JP. General features of intracerebral hemorrhage. Stroke 1986; 497-521.

20. Tuhrim S, Horowitz DR, Sacher M, Godbold JH. Validation and comparison of models predicting survival followingintracerebral hemorrhage. Crit Care Med 1995; 23: 950-954.

21. Davis SM, Broderick J, Hennerici M, Brun NC, Diringer MN, Mayer SA, Begtrup K, Steiner T. Hematoma growth is a determinant of mortality and poor outcome after intracerebral hemorrhage. Neurology 2006; 66: 1175-1181.

\section{*Correspondence to}

Ömer Aykanat

Department of Neurosurgery

Medical Faculty

Ahi Evran University

Turkey 